\title{
Physiotherapy Intervention and Factors Affecting Rehabilitation of A Patient with Adhesive Capsulitis Following Mastectomy Surgery
}

\author{
Dhanashri Ghordadekar ${ }^{1}$, Renuka Dhole ${ }^{1}$, Madhura Darware ${ }^{1}$ and Gaurav Mishra ${ }^{2}$ \\ ${ }^{1}$ Intern, Ravi Nair Physiotherapy College, Datta Meghe Institute of Medical \\ Sciences, Wardha, Maharashtra, India - 442001 \\ ${ }^{2}$ Department of Radiodiagnosis, Jawaharlal Nehru Medical College, \\ Datta Meghe Institute of Medical Sciences, Sawangi (M), Wardha. \\ Corresponding author email: ghordadekardhanashri@gmail.com
}

\section{ABSTRACT}

Breast cancer is the most common cancer among Indian females having a prevalence of about 25.8 and mortality rate of around 12.7 per 100,000 women. Age related abnormal changes within certain cells increases the risk of developing breast cancer.The primary treatment of breast cancer is surgery. The consequences of surgery includes a range of upper limb dysfunctions. This 42 years-oldfemale, reported with right anterior chest pain andlimited range of motion in the right shoulder. She reported history of unilateral modified radical mastectomy. The case was diagnosed as adhesive capsulitis of right shoulder with muscular fibrosis of anterior chest wall. Intervention was targeted on strengthening and stabilization of scapular and shoulder muscles and mobilizationgleno-humeral joint. Physiotherapy was given for 3-4 days per week for 12 weeks. Also home exercise program and patient education sessions were organized . The primary outcome measures includedpassive range of motion, pain rating, MMT, and Barthel index for functional assessment. Total 12 weeks intervention helped to improve passive and active range of motion. Also, shoulder and scapular muscle strength wasimprovedwith reduction in pain. Functional mobility was improved as assessed by Barthel index. The physical therapy rehabilitation for post-operated breast cancer survivors can be quite helpful to cope with the injury. Additional patient education may be required to prevent dysfunction and promote mobility of shoulder joint.

KEY WORDS: BREAST CANCER, POST -OPERATIVE, ADHESIVE CAPSULITIS, RADICAL MASTECTOMY SURGERY, PHYSIOTHERAPY REHABILITATION.

\section{INTRODUCTION}

Breast cancer has ranks to be thetopmost cancer among Indian females. The age adjusted rate of breast cancer is 25.8 with mortality rate of 12.7 per 100,000 women. With increasing age,women have an increasedrisk of developing breast cancer as a result of abnormal changes in certain cells. Other risk factors include post-menopausal hormonal therapy, inadvertent use of oral contraceptives,

Biosc Biotech Res Comm P-ISSN: 0974-6455 E-ISSN: 2321-4007

\section{crossef}

Identifiers and Pagination

Year: 2021 Vol: 14 No (6) Special Issue

Pages: $62-65$

This is an open access article under Creative

Commons License Attribn 4.0 Intl (CC-BY).

DOI: $h t t p: / / d x . d o i . o r g / 10.21786 / b b r c / 14.6 .15$ family history, alcohol consumption frequency and ethnicity1. Though the mortality ratehasdeclined in recent past owing to increased screening techniques and improved treatment options, post-operative complications after treatment affects the quality of life (Jemal et al., 2011).

Surgery being the primary treatment modality for breast cancer is usually associated with a number of upper limb dysfunction. As per (De Grof et. al., 2015 ; Beursken et. al., 2007) patients with surgical intervention for breast cancer should be given active exercise which are effective in treatment of impairments and improving range of motion (ROM), ultimately resulting in improvement in quality of life. This case of post-operative breast surgery was given physiotherapy interventions which included

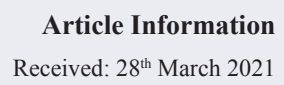

ccepted after revision: $2^{\text {th }}$ May 2021 
exercisestargeted at rehabilitation of a patient with adhesive capsulitis.

Case Description: The patient was 42 years old female, resident of Gopal Nagar, Nagpur. Housewife by occupation. No history of alcohol consumption, tobacco chewing and smoking. The patient was diagnosed as case of adhesive capsulitisand referred to physiotherapy department by surgery department of LMC. The patient reported decreased range of motion of right shoulder along with pain in anterior chest wall. The patient had history of invasive lobular carcinoma of right breast 4 months back5. Invasive lobular carcinoma usually begins in the skin and spreads to the breast tissue. Stage 1 invades up to three lymph nodes6.The patient was treated with right mastectomy and lumpectomy after 2 months of diagnosis. Patient has no significant past history and family history.

The patient had maintained a guarded position for about a month after surgery and did minimal movements of right upper extremity. As a result, there was decreased range of motion and fibrosis of the anterior chest wall musculature. The patient reported that pain and loss of motion gradually increased over time. It affected her activities of daily living and she sought out medical attention advise.The patient also presented with psychological symptoms for which she was referred for counseling to Psychology department.

Examination and evaluation: Initially, patient filled Barthel index in which she scored 80 indicating "moderate" dependency on caregiver. This is a ordinal scale used to measure performance in activities of daily living (ADL). After filling out the scale further assessment was done. Cardiovascular and respiratory system was seen to be normal during general examination. During integumentary examination, tissues around right axilla, right anterior chest wall was found to be hypomobile and fibrosed. The incision site was blue-purple coloured, no sign of infection.

Table 1
$\begin{aligned} & \text { Shoulder } \\ & \text { motions }\end{aligned}$

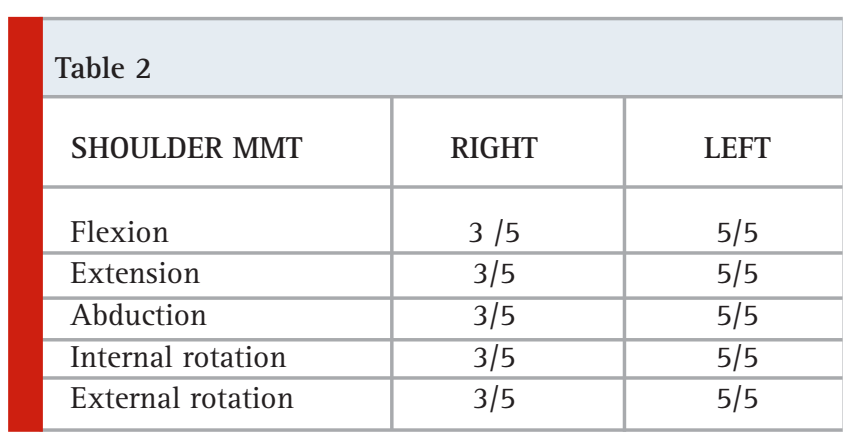

In the axillary region, the patient was developing Axillary Webbing Syndrome (Winicour, 2013) which causes limitations of shoulder range of motion. Numerical Pain Rating Scale (NPRS) was used to assess pain on which patient marked $4 / 10$ during rest and $8 / 10$ during movement of affected shoulder above 90 degree. Patient had tenderness over incision site, tenderness was grade 3 that is palpation is tender, patient winces and withdraws the limb. Range of motion was assessed using goniometer. The limitations in right shoulder ROM followed the capsular pattern. There was normal ranges in all direction for left shoulder. Manual Muscle Testing (MMT) was done to measure muscles strength of right and left shoulder muscles. Reduced in strength of right upper limb muscles was seen.
Girth measurement was done on both the upper limb to assess any swelling as lymph nodes of right side was removed. No significant difference was noticed. Physical examination confirmed the diagnosis of adhesive capsulitis. Intervention was designed to increase shoulder mobility and strength, scar tissue mobilization and overall increase in functional use of affected arm.

Plan of Care: Short term goal included patient's education about signs and symptoms of lymphadenopathy, prevention strategies, self-examination of breast, home exercise program, improving shoulder ROM and decrease in pain. Long term goal included improving ROM of shoulder in all direction, patient should be able to make functional use of limb, scar tissue should be mobilized and improving body posture. Re-evaluation was done every 3 weeks, to monitor changes and to see if the given intervention is beneficial for the patient. The other interventions included mobilizations of gleno-humeral joint along with strengthening and stretching exercises. Patient was educated about proper body mechanics and posture, lymphedema and a home exercises.

Intervention: All the interventions given was directed to improving shoulder range of motion, increase strength and decrease pain. Each session was started by 10-15 minutes of warm-up period followed by $20-$ 30 minutes of prescribed exercise and manual therapy 
then finally ended by 10 minutes of cool-down period. Manual therapy included scar tissue mobilization, to improve pliability of tissue. Ultrasound was given for 5-7 minutes then deep friction massage was done. This helped increase the shoulder range of motion. Next gleno-humeral mobilization was done, initially grade 1-2 mobilization was given then grade 3-4 was given which was helpful in breaking adhesions.

Then hydrocollater packs were applied over shoulder region for 5-10 minutes which was followed by stretching of shoulder girdle muscle, pectoral muscles were performed. Initially manual stretching was done then patient was taught self-stretching and each stretch was hold for 20 seconds and repeated 5-7 times. Lastly, strengthening exercises were done, initially assistance was provided and done in gravity eliminated plan later once strength was gain, against gravity with body weight was done with minimal assistance. Once full range was achieved resistance training was started. Resistance was provided using theraband, weight cuffs, manual resistance, dumbbells. Home exercise program was given to improve functional use of limb.

\begin{tabular}{|c|c|c|c|c|}
\hline \multicolumn{5}{|l|}{ Outcome } \\
\hline & PAIN & $\begin{array}{c}\text { ROM } \\
\text { (affected limb) } \\
\text { Active ROM }\end{array}$ & $\begin{array}{c}\text { MMT } \\
\text { (affected limb) }\end{array}$ & Barthel index \\
\hline \multirow[t]{4}{*}{3 weeks } & $4 / 10$ on rest. & Flexion- 120 & Flexion- $4 / 5$ & \multirow[t]{4}{*}{85} \\
\hline & 7/10 during & Abduction- 100 & Abduction- $3 / 5$ & \\
\hline & \multirow[t]{2}{*}{ movement. } & Internal rotation- 40 & Internal rotation- $4 / 5$ & \\
\hline & & External rotation- 35 & External rotation-3/5 & \\
\hline \multirow[t]{4}{*}{6 weeks } & No pain on rest. & Flexion- 160 & Flexion- $4 / 5$ & \multirow[t]{4}{*}{90} \\
\hline & \multirow[t]{3}{*}{ 5/10 on movement. } & Abduction- 140 & Abduction- 4/5 & \\
\hline & & Internal rotation- 67 & Internal rotation- $4 / 5$ & \\
\hline & & External rotation- 43 & External rotation-4/5 & \\
\hline \multirow[t]{4}{*}{12 weeks } & No pain on rest. & Flexion- 178 & Flexion- 5/5 & \multirow[t]{4}{*}{95} \\
\hline & \multirow[t]{3}{*}{ 2/10 during movement. } & Abduction- 175 & Abduction- 5/5 & \\
\hline & & Internal rotation- 84 & Internal rotation- 5/5 & \\
\hline & & External rotation- 64 & External rotation-4/5 & \\
\hline
\end{tabular}

\section{DISCUSSION}

$\overline{\text { It's important to eliminate and prevent re-occurance of }}$ cancer once the patient is diagnosed. Patient can fail to recognize the musculoskeletal complication that can occur after breast cancer surgery including potential upper limb dysfunction. In study by Engel and colleagues8 there is significant decline in quality of life after breast cancer surgery. It is important to monitor patients with breast cancer surgery for signs and symptoms of upper limb dysfunction and prevent further disability. In a 2011 study, (Harrington et al., 2011)18 found that shoulder function, ROM, and strength were clinically important in determining severity of impairment in breast cancer patients. Once dysfunction is identified early intervention to reduce pain, improve strength and range of motion should be carried out by strengthening, stretching, soft tissue mobilization, manipulation and using different electrical modalities.

In a research conducted by (Harrington et al, 2011), the author conducted a study in which two groups of women were selected where one group received early physiotherapy intervention after breast surgery and one group didn't, both the groups were compaired after regular interval and the author concluded that the group which received physiotherapy were having less post-surgery complication and disability. (Wankhade et al, 2019) recommended a multidisciplinary approach to treatment.. A number of studies on carcinoma breast were reported. Studies on shoulder pain and joint morphology diagnostics and treatment were reviewed (Saoji et al, 2020; Singh et al., 2019; Deshpande, et al., 2018). Also studies on breast carcinoma mastectomy (Yadav et al., 2020) and physiotherapy modalities for alike problems were reviewed. This article suggest the need for physiotherapy post breast cancer surgery to prevent any upper limb dysfunction and complication. It is also important to give psychological counseling to patients to decrease emotional and mental stress caused after surgery and cope with the new changes in body. This physical and psychological intervention would help in improving quality of life of patient. There is requirement of multidisciplinary approach to establish a positive outcome and improved quality of life.

\section{REFERENCES}

Aalam, Azeem Javed, Pankaj Gharde, And Meenakshi Yeola. 2020 A Comparative Study To Evaluate The Effect Of Obliteration Of Dead Space Of Mastectomy Flaps. Medical Science 24: 1042-51.

Aditi, G., S. Samarth, V. Sunita, A. Sourya, J. Miheer, And J.M. Kumbhare. 2019 Utility Of Microvessel Density And It's Correlation With Nottingham Prognostic 
Index In Carcinoma Breast.” International Journal of Pharmaceutical Research 11(4): 2013-17. Https://Doi. Org/10.31838/Ijpr/2019.11.04.502.

Anand, Anupam Surya, And Raju Kamlakarrao Shinde. 2020 To Compare The Effects Of Adjuvant And Neoadjuvant Chemotherapy On Outcome Of Stage Iii Carcinoma Breast. Journal Of Evolution Of Medical And Dental Sciences-Jemds 9: 496-501. Https://Doi. Org/10.14260/Jemds/2020/112.

Beurskens C, Van Uden C, Strobbe L, Oostendorp R, Wobbes T. 2007 The Efficacy Of Physiotherapy Upon Shoulder Function Following Axillary Dissection In Breast Cancer, A Randomized Controlled Study. Bmc Cancer. 7(1):166.

Breast Cancer Risk In American Women. National Cancer Institute. 2016. Available At: Http://Www.Cancer.Gov/ Types/Breastlrisk-Fact-Sheet. Accessed May 26,2016 De Groef A, Van Kampen M, Dieltjens E Et Al. 2015, Effectiveness of Postoperative Physical Therapy For Upper-Limb Impairments After Breast Cancer Treatment: A Systematic Review. Archives Of Physical Medicine And Rehabilitation. 96(6):1140-1153. Doi: 1 0.1016/J.Apmr.2015.01.006.

Deshpande, S., S. Phatak, G. Marfani, N. Gupta, S. Daga, And S. Samad. 2018 Sonographic Evaluation Of Painful Shoulder And Its Comparison With Clinical Diagnosis.” Journal Of Datta Meghe Institute Of Medical Sciences University 13: 12-15.

Engel J, Kerr J, Schlesinger-Raab A, Sauer H, Holzel D. Erratum, Axilla 2003, Surgery Severely Affects Quality Of Life: Results Of A 5-Year Prospective Study In Breast Cancer Patients. Breast Cancer Res Treat 80(2):233233.

Harrington S, Padua D, Battaglini C Et Al. 2011 Comparison of Shoulder Flexibility, Strength, And Function Between Breast Cancer Survivors And Healthy Participants. Journal Of Cancer Survivorship 5(2): 167174.

Harrington S, Padua D, Battaglini C Et Al. 2011 Comparison Of Shoulder Flexibility, Strength, And Function Between Breast Cancer Survivors And Healthy Participants. Journal Of Cancer Survivorship. 5(2): 167174.

Hemant, L.H., H. Keshao, V. Sunita, And C.S. Gode. 2019 Correlation Of Total Serum Ldh Levels With Differentiation of Breast Carcinoma.” International Journal of Pharmaceutical Research 11: 1211-15. Https://Doi.Org/10.31838/Ijpr/2019.11.01.214.

Ilc -Invasive Lobular Carcinoma. Breastcancerorg. 2016. Available At: Http://Www.Breastcancer.Org/Symptoms/ Types/Ilc.

Jemal A, Bray F, Center M, Ferlay J, Ward E, Forman
D. 2011, Global Cancer Statistics. Ca: A Cancer Journal For Clinicians. 61 (2):69-90.

Kishor, T.A., H.K. Madhavrao, V. Sunit, And P. Palsodkar. 2019 Study Of Androgen Receptor As A Quadruple Marker In Breast Carcinoma. International Journal Of Pharmaceutical Research 11: 1173-78. Https://Doi. Org/10.31838/Ijpr/2019.11.01.208.

Latchoumi, T.P., Ezhilarasi, T.P. and Balamurugan, K., 2019. Bio-inspired weighed quantum particle swarm optimization and smooth support vector machine ensembles for identification of abnormalities in medical data. SN Applied Sciences, 1(10), pp.1-10.

Meshram, P., A. Pawaskar, And A. Kekatpure. 2020 3d Ct Scan-Based Study Of Glenoid Morphology In Indian Population: Clinical Relevance In Design of Reverse Total Shoulder Arthroplasty. Journal Of Clinical Orthopaedics And Trauma 11: S604-9. Https://Doi. Org/10.1016/J.Jcot.2020.03.001.

Mishra, P., S. Vagha, S. Shukla, And S.S. Chaudhari. 2019 Correlation Of Cytokeratin Expression With Bloom Richardson Grading Of Carcinoma Breast In Rural Setup.” International Journal of Pharmaceutical Research 11, : 1844-48.

Saoji, K.K., V. Gawande, And R. Dulani. 2020 A Comparative Study Of Disability And Pain Assessment By Shoulder Pain And Disability Index (Spadi) Score In Patients Of Adhesive Capsulitis Treated By Hydrodilatation With And Without Corticosteroids." International Journal of Current Research And Review 12: 35-40.

Singh, R., And A. Singam. 2019 Comparison Between Supraclavicular And Interscalene Brachial Plexus Block In Patients Undergoing Shoulder Surgery." Journal of Datta Meghe Institute Of Medical Sciences University 14:175-78.

Stages 0 \&t 1: The National Breast Cancer Foundation. 2016. Available At: Http://Www . Nationalbreastcancer. Ora/B Reast -Cancer-Staae-O-A Nd-Staae-1 . Accessed May 12, 2016.

Wankhade, R., V. Gupta, And A. Belsare. 2019 Role Of Ki 67 In Pathological Prognostic Staging Of Breast Cancer. International Journal of Pharmaceutical Research 11: 1469-73. Https://Doi.Org/10.31838/ Ijpr/2019.11.03.164.

Winicour J. 2013 What Is Cording? National Lymphedema Network. 25(2):1-3

Yadav, Madhumita, Nupur Thombare, Waqar M. Naqvi, And Ashish W. Bele. 2020 Impact Of Physiotherapy Rehabilitation Program On Post-Operative Stiffness of Supraspinatus Tendinitis." Journal of Evolution Of Medical And Dental Sciences-Jemds 9, No. 33: 2403-5. 